\title{
An Interprofessional Consensus of Core Competencies for Prelicensure Education in Pain Management: Curriculum Application for Nursing
}

\author{
Keela Herr, PhD, RN, AGSF, FAAN [Professor and Associate Dean for Faculty], \\ College of Nursing, University of lowa, lowa City, lowa \\ Barbara St. Marie, PhD, ANP, GNP, ACHPN [Associate Faculty], \\ College of Nursing, University of lowa, lowa City, lowa \\ Debra B. Gordon, DNP, RN-BC, ACNS-BC, FAAN [Co-Director], \\ Harborview Integrated Pain Care Program, Anesthesiology \& Pain Medicine, Harborview Medical \\ Center, University of Washington, Seattle, Washington \\ Judith A. Paice, PhD, RN, FAAN [Director], \\ Cancer Pain Program, Division of Hematology-Oncology, Northwestern University, Feinberg \\ School of Medicine, Chicago, Illinois \\ Judy Watt-Watson, PhD, RN [Professor Emeritus], \\ Lawrence S. Bloomberg Faculty of Nursing, Faculties of Medicine and Dentistry, University of \\ Toronto, Toronto, Ontario, Canada \\ Bonnie J. Stevens, PhD, RN, \\ Signy Hildur Eaton Chair in Pediatric Nursing Research, Lawrence S. Bloomberg Faculty of \\ Nursing, Faculties of Medicine and Dentistry, University of Toronto, Toronto, Ontario, Canada \\ Debra Bakerjian, PhD, RN, FNP, FAANP [Senior Director], and \\ Nurse Practitioner/Physician Assistant Clinical Education and Practice and Associate Adjunct \\ Professor, Betty Irene Moore School of Nursing, University of California-Davis, Sacramento, \\ California
}

Heather M. Young, PhD, RN, FAAN [Associate Vice Chancellor for Nursing, and Dean and Professor]

Betty Irene Moore School of Nursing, University of California-Davis, Sacramento, California

\section{Abstract}

Background-Ineffective assessment and management of pain is a significant problem. A gap in prelicensure health science program pain content has been identified for the improvement of pain care in the United States.

Copyright $\odot$ SLACK Incorporated

Address correspondence to Keela Herr, PhD, RN, AGSF, FAAN, Professor and Associate Dean for Faculty, College of Nursing, University of Iowa, 306 CNB; 50 Newton Road, Iowa City, IA 52242; Keela-herr@uiowa.edu.

The authors have disclosed no potential conflicts of interest, financial or otherwise. 
Method-Through consensus processes, an expert panel of nurses, who participated in the interdisciplinary development of core competencies in pain management for prelicensure health professional education, developed recommendations to address the gap in nursing curricula.

Results-Challenges and incentives for implementation of pain competencies in nursing education are discussed, and specific recommendations for how to incorporate the competencies into entry-level nursing curricula are provided.

Conclusion-Embedding pain management core competencies into prelicensure nursing education is crucial to ensure that nurses have the essential knowledge and skills to effectively manage pain and to serve as a foundation on which clinical practice skills can be later honed.

Pain is one of the most prevalent and significant problems that health professionals, including nurses, address in practice; yet, continuing evidence suggests that it is inadequately managed, regardless of the population or setting of care (Institute of Medicine [IOM], 2011). However, prelicensure (undergraduate) health science programs provide limited pain content, which does not ensure that graduates have the knowledge, skills, or clinical competence to provide quality pain care to patients across the continuum of health care throughout the lifespan (Frenk et al., 2010; IOM, 2011).

Core competencies in pain management for prelicensure health professional education were recently established (Fishman et al., 2013), and they map well to the International Association for the Study of Pain's interprofessional pain curricula (2012). These competencies delineate expectations for minimally acceptable capabilities for pain management for graduating health profession students, regardless of discipline. They provide a basis for preparing students to successfully apply knowledge and skills in a manner that supports inter-professional team contributions in providing quality pain care in the real world. The competencies address four important domains with varying levels of expectations, depending on the discipline. These domains are (a) multidimensional nature of pain, (b) pain assessment and measurement, (c) management of pain, and (d) context of pain.

The purpose of this article is to identify how core competencies for pain articulate with the American Association of Colleges of Nursing's baccalaureate Essentials (AACN, 2008), to advocate for implementation in nursing education, and to provide specific recommendations for how to incorporate the competencies into entry-level nursing curricula. Embedding pain management core competencies within prelicensure nursing education is critical to ensure that nurses have the essential knowledge and skills to effectively manage pain and to serve as a foundation on which clinical practice skills can be honed.

\section{PAIN CONTENT DESERVES A PRIORITY PLACE IN PRELICENSURE NURSING CURRICULA}

Pain is a multidimensional experience that negatively impacts all facets of an individual's life, the health care system, and society as a whole. Effective pain management is considered a moral imperative, a professional responsibility, and the duty of health professionals (IOM, 2011). Key dimensions of pain relevant to nursing science and theories are the sensory, 
emotional, spiritual, behavioral, cognitive, and sociocultural aspects. Pain and symptom management are among the principles of basic nursing care indicated by The Essentials of Baccalaureate Education for Professional Nursing Practice (AACN, 2008). Relief of pain and suffering is essential to patient-centered care.

Pain qualifies as a public health problem due to its current and growing prevalence and negative repercussions. In the United States, more than 100 million individuals across all age groups experience chronic pain annually, with more than 50 million being partially or totally disabled by pain (IOM, 2011; Tsang et al., 2008). The IOM (2011) estimates the annual cost of pain and its sequelae to be in the billions of dollars. Despite the high prevalence of patients with pain, fewer than $50 \%$ of patients with moderate to severe pain obtain adequate pain relief, which is particularly notable in vulnerable populations, including children and older adults (Gianni et al., 2010; Herr \& Titler, 2009; Patel, Guralnik, Dansie, \& Turk, 2013; Taylor, Boyer, \& Campbell, 2008). More than 73 million surgeries are performed in the United States annually, and more than $75 \%$ of individuals undergoing these procedures report moderate to extreme pain during the immediate postsurgical period, with 74\% still experiencing these levels of pain after discharge from the facility (Gan, Habib, Miller, White, \& Apfelbaum, 2014). Inadequately treated pain after surgery inhibits healing and increases the risk of myocardial ischemia, stroke, bleeding, and other complications through mechanisms such as increased heart rate, systematic vascular resistance, and circulating stress-related hormones (IOM, 2011).

The likelihood of experiencing a transition from acute to chronic pain is influenced in part by the adequacy of acute pain relief (Choinière et al., 2014; IOM, 2011). Chronic pain is estimated to occur in one of four individuals and is likely to continue to rise due to increases in obesity-associated painful chronic conditions, the increased survival rate from catastrophic injuries, the transition of many illnesses or injuries previously considered as terminal conditions to chronic illnesses, the aging population, and other factors. For example, van den Beukenvan Everdingen's et al. (2007) review of studies published between 1996 and 2005 found that the prevalence of pain during active anticancer treatment (59\%) was nearly as great as that found in advanced, metastatic, or terminal disease (65\%). One third of survivors cured of their cancer had pain, and more than one third of these patients had moderate or severe pain (van den Beuken-van Everdingen et al., 2007). Clearly, pain challenges are significant, and the complex multifaceted issues of pain and its management are best addressed through interdisciplinary collaborations. However, consistent implementation of evidence-based pain practices across care settings and populations is lacking, and improvements in pain care in the United States are essential.

Regardless of the patient population or clinical setting, all nurses will encounter patients needing pain assessment and management. In service to society, nurses play a pivotal role in preventing, screening, and conducting comprehensive assessment and reassessment of pain, as well as promoting evidence-based practices and contributing to and leading effective inter-professional teams. Therefore, nurses at entry to practice must have the clinical competencies for assessing and managing pain, regardless of the population group or setting (Registered Nurses' Association of Ontario, 2013). Integration of pain management core 
competencies within prelicensure curricula is a starting point for ensuring that all nurses have the necessary knowledge and skills to help reduce this public health crisis.

\section{CURRENT STATUS OF PAIN MANAGEMENT INCLUSION IN PRELICENSURE NURSING CURRICULA}

Understanding of the phenomenon of pain, its immediate and long-term consequences, and its effective management strategies is lacking or is minimal in many health science curricula, including those for nursing (Briggs, Carr, \& Whittaker, 2011; Watt-Watson et al., 2009). This lack of knowledge and effective translation into a usable form for practitioners raises the following question: Do graduates have sufficient knowledge and skills to be competent in giving appropriate pain management to their patients?

Multiple studies have identified deficits in nursing knowledge and skills related to pain management; the majority of these studies have examined nursing knowledge, skills, and management in specialty clinical environments such as cancer pain (Wilkes, Lasch, Lee, Greenhill, \& Chiri, 2003); surgical nurses' knowledge (Puls-McColl, Holden, \& Buschmann, 2001); and in the care of older adults (Sloman, Ahern, Wright, \& Brown, 2001) and children (Stanley \& Pollard, 2013). However, those studies did not address pain curricula in prelicensure nursing programs.

To better understand the current state of pain content in nursing curricula in the United States, a literature review was conducted using pain, pain management nursing, pain curricula, pain knowledge, pain competency, prelicensure nursing, undergraduate nursing, nursing students, and baccalaureate nursing as search terms for the PubMed ${ }^{\circledR}$ and CINAHL $^{\circledR}$ Plus with Full Text databases. Studies were included if they were about U.S. programs, written in English, and conducted within the past 10 years. Although several studies were related to pain knowledge in clinical environments and postgraduate curricula, only five studies examined general pain knowledge in the prelicensure environment (Briggs, 2010; Doorenbos et al., 2013; Plaisance \& Logan, 2006; Samuels \& Leveille, 2010; Shaw \& Lee, 2010). Four of the studies discussed student attitudes, knowledge, and experiences, and only one had a specific focus on prelicensure curricula (Doorenbos et al., 2013). Of note, a greater number of international studies have examined student knowledge and attitudes related to pain (Al Khalaileh \& Al Qadire, 2013; Chiu, Trinca, Lim, \& Tuazon, 2003; Prem et al., 2011; Rahimi-Madiseh, Tavakol, \& Dennick, 2010); however, similar to the U.S. review, few have examined the quantity or nature of pain content within the nursing curricula. Only two international studies - one from Canada (Watt-Watson et al., 2009) and one from the United Kingdom (Briggs et al., 2011)—surveyed prelicensure pain curricula in health sciences students.

The main focus of the two international studies (Briggs et al., 2011; Watt-Watson et al., 2009) was to describe existing pain content in the prelicensure curricula in multiple health profession programs (dentistry, medicine, pharmacy, nursing), and both reported similar findings that the amount of time dedicated to pain in the curricula varied across programs at the various campuses. The Canadian study (Watt-Watson et al., 2009) found that only one third of the Canadian universities' health sciences programs sampled could identify 
designated time for pain content. Individuals who responded to the survey from the nine nursing programs reported a proportionately low mean of 31 hours (range $=0$ to 109 hours) of designated mandatory pain content across 2 to 4 years of their curricula. Briggs et al. (2011) targeted 19 institutions in the United Kingdom, with 108 prelicensure programs in multiple disciplines. Of the 30 nursing programs that responded, a median of only 10.2 hours (range $=2$ to 36 hours) was devoted to pain content.

As one of 12 sites funded by the National Institute of Health Pain Consortium to develop the Centers of Excellence in Pain Education, the University of Washington examined curricula in six prelicensure health sciences programs serving students within their Washington, Wyoming, Alaska, Montana, and Idaho networks and confirmed the paucity of pain content in the majority of these programs (Doorenbos et al., 2013). The physician assistant program at the University of Washington reported the highest number of hours (145), which represented $17 \%$ of their curriculum. The prelicensure nursing program at the University of Washington reported only 8 hours of pain content across 2 years, representing just $1 \%$ of their training hours (Doorenbos et al., 2013). In response to the significant gaps found in the study of their own institutions based on existing competencies for prelicensure programs and the recently published interprofessional competencies (Fishman et al., 2013), the authors of the current study recommend that programs should develop a blueprint of their existing curriculum as a foundation for implementation of future improvements that incorporate both professional prelicensure and interprofessional competencies. The need is clear to improve and standardize pain education in basic content, as well as the interprofessional education competencies in prelicensure nursing programs.

\section{CORE COMPETENCIES IN PAIN MANAGEMENT}

\section{Goal of Having Core Competencies in Pain Management in Prelicensure Curricula}

Although professional standards strongly influence curricula, pain competencies have been minimally developed or not tailored to the requirements for licensure of nurses (WattWatson et al., 2013). Pain competencies are measureable outcomes of learning, which regulatory and accreditation bodies can use to guide the curricula of health science faculty to ensure that beginning practitioners are adequately prepared (Watt-Watson \& Siddall, 2013).The previous absence of core pain management competencies may help to explain the limited attention to pain content across nursing programs to date.

Inadequate pain education across health professions has been continually documented and is a barrier to providing high-quality pain care to the population. Having the same basic foundation of pain education for all health care professionals can promote interprofessional collaboration and partnership to address the challenges of effective pain management and promote improved clinical outcomes for those experiencing pain. The optimal goal is to ensure that all prelicensure nursing students achieve core pain management competencies prior to graduation from their prelicensure program. The American Nurses Association's (ANA) Code of Ethics for Nurses (2015) clearly indicates the importance of the relief of pain and suffering, thus establishing this knowledge and skill set as a priority. 
Nurse leaders need to ensure that students (a) have the most up-to-date knowledge and skills to manage pain in a way that is consistent with the highest professional ethical standards (Watt-Watson \& Murinson, 2013) and (b) are skilled in applying this knowledge in practice. The commitment of educators, academic administrators, and professional certifying organizations is needed to address curricular changes and mandates that will bring this goal to reality.

\section{Development of Interprofessional Core Competencies for Pain Management}

Through an interprofessional process, core competencies in pain assessment and management were developed to provide guidance related to prelicensure pain education across health care professions. A structured process was used with the following steps:

- Establishing an executive interprofessional committee composed of seven experts in pain management and education that synthesized the current evidence and existing profession-based competencies and then developed a draft set of candidate competencies.

- Establishing an international expert interprofessional pain competencies consensus group, with representation by 29 individuals from all major health professions, that reviewed all draft materials and, through an onsite consensus process, recommended a final set of competencies.

Details of the methods of the interprofessional process used are available in Fishman et al. (2013). From the initial draft of 40 competencies, 21 final core pain assessment and management competencies were affirmed and organized under four domains. The first three domains highlight foundational knowledge and skills required by all clinicians to identify, assess, prevent, and treat pain. The fourth domain emphasizes application of effective pain management practices within various populations and contexts. The four domains and competencies and a set of core values and principles essential to implementing the core competencies are available at https://www.ucdmc.ucdavis.edu/paineducation.

\section{INTEGRATING PAIN MANAGEMENT CORE COMPETENCIES INTO PRELICENSURE NURSING CURRICULA}

Competency-based education shifts the focus of the learner's perspective by transferring assessment from what has been successfully taught to what has been successfully learned (Arwood et al., 2014; Gordon, 2010). The pain management core competencies for prelicensure education (Fishman et al., 2013) were developed using multiple levels of learning designed to assess the performance of clinical concepts while also considering the foundational knowledge that is specific to each profession.

The pain management competencies can be mapped within existing curricula, with the knowledge-level competencies serving as the building blocks that support the learning of clinical concepts. Competencies should be aligned with the stated objectives of a course and can be measured through methods such as oral or written examinations, case-based learning activities, observed clinical encounters, and reflective essays, with observed behavior being the focus for evaluating clinical competencies (Gordon, 2010). To assess competency, 
multiple measurement points of varying complexity should assess the student in a range of environments and with diverse cases (Arwood et al., 2014).

For example, Domain Two, Competency Two states that the learner must "describe patient, provider, and system factors that can facilitate or interfere with effective pain assessment and management" (Fishman et al., 2013, p. 976). The initial introduction to this competency might not be pain specific and could include a reflective essay assignment, requiring the learner to demonstrate knowledge of various patient (from a biopsychosocial-spiritual approach), provider, and system factors that impact care. A second point of assessment might include an assignment to conduct a chart audit through the electronic medical record to identify individuals reporting pain (including pain intensity, location, and quality) and factors that might impact delivery of care. Demonstrated proficiency in this competency serves as a foundation for becoming adept at such clinical concepts as does Domain Four, Competency Four: "Implement an individualized pain management plan that integrates the perspectives of patients, their social support systems and health care providers in the context of available resources" (Fishman et al., 2013, p. 976). Assessment of this competency might include observed patient encounters incorporating pain care in different settings and in diverse clinical situations and include how interprofessional care is applied. These encounters, taken collectively, should demonstrate the learner's skills, ability, and knowledge to perform the competency prior to completing the educational program. The ultimate goal is the habitual and judicious use of communication, knowledge, technical skills, clinical reasoning, emotions, values, and reflection in daily practice (Epstein \& Hundert, 2002).

Another anchor for the pain competencies in prelicensure curricula is the Essentials for Baccalaureate Education (AACN, 2008), which provides professional standards for nursing curricula and a framework for course design. Inclusion of the pain management core competencies should meet standards in at least three of the Essentials. Essential III (Scholarship for Evidence-Based Practice) expects that the baccalaureate graduate is prepared to:

participate in the process of retrieval, appraisal, and synthesis of evidence in collaboration with other members of the healthcare team to improve patient outcomes...and... integrate evidence, clinical judgment, interprofessional perspectives, and patient preferences in planning, implementing, and evaluating outcomes of care. (AACN, 2008, p. 16)

Requisite evidence exists in all four domains of the pain management core competencies to contribute to optimal patient outcomes in regard to symptom management and quality of life.

Essential VI (Interprofessional Communication and Collaboration for Improving Patient Health Outcomes) calls for "using inter- and intraprofessional communication and collaborative skills to delivery evidence-based, patient-centered care" (AACN, 2008, p. 22). Consistent with this standard, the multidimensional experience of pain requires an integration of assessment and interventions across disciplines. 
Finally, Essential VII (Clinical Prevention and Population Health) explicates the standards for assessment, intervention, and collaboration to address health problems, with attention to beliefs, values, attitudes, and practices of individuals, families, groups, communities, and populations. It specifies the "use of behavioral change techniques to promote health and manage illness," and calls for "collaboration with other healthcare professionals and patients to provide spiritual and culturally appropriate health promotion and disease and injury prevention interventions" (AACN, 2008, p. 24). As described in the pain competencies, pain assessment and management is highly contextual and requires an appreciation for the diversity of background, beliefs, and experiences to provide person-centered and familycentered care in the case of children or other populations, where families are an integral part of the provider team.

The pain management core competencies represent relevant content to meet the AACN baccalaureate Essentials and also provide an opportunity for innovation in educational approaches. Because of the complexity of the clinical situations surrounding pain, these are particularly amenable to innovative teaching approaches for education, including the use of case-based learning and simulated clinical experiences. The challenges of pain assessment and management are biopsychosocial and interpersonal, often posing ethical and professional dilemmas worthy of deep discussion and exploration. These situations are ideal for interprofessional learning as an issue that crosses disciplines and is best informed by diverse perspectives. Although core knowledge of pain warrants a cohesive presentation in the form of modules or a stand-alone course, integration of knowledge about pain is required across the curriculum, as it is found in a variety of clinical conditions across the lifespan. Strategies for incorporating the core pain management competencies (Table 1), with definitions of teaching methods (Table 2), are used, and additional resources link are provided (Table A; available in the online version of this article).

\section{Resources and Exemplars for Incorporating Pain Competencies Into Prelicensure Nursing Curricula}

To support nursing faculty's incorporation of core pain competencies into the curricula, awareness and accessibility of existing resources is essential. A collection of open access Web resources, which have been expert reviewed by professional pain organizations to advance pain education and clinical pain practice, is provided in additional resources links

(Table A). These resources contain curricular outlines and content for integration into health care education. As noted previously, the International Association for the Study of Pain (2012) developed a separate curriculum for interprofessional education that endorses the process for health care disciplines learning together. Most recently, the National Institutes of Health recognized the existing gap in the pain-related tools needed to guide faculty and established the Centers of Excellence in Pain Education that are currently developing Webbased case modules that are accessible to any health educator for use in the efforts to achieve the core pain competencies (http://painconsortium.nih.gov/coepes.html). 


\section{CHALLENGES TO INCORPORATING PAIN COMPETENCIES INTO NURSING EDUCATION}

Core pain management competencies are now available to establish regulatory requirements and support the expectation that pain management content will be included in health professions curricula (Fishman et al., 2013; Watt-Watson \& Murinson, 2013). However, many challenges exist that hinder the progress of the pain education agenda. The foundation of these challenges may be the lack of appreciation of the consequences of pain in tandem with the well-ensconced and seasoned health professional attitudes and behaviors about pain. In addition, resistance from educators about inserting new content into already packed curricula is reflected in the IOM's monograph on pain in America:

Curricula for all health professions are full, and advocates of many important causes compete for a greater share of students' and clinicians' valuable educational time. Yet, despite the large role that care of patients with pain will play in their daily practice, many health professionals appear underprepared for and uncomfortable with carrying out this aspect of their work. These professionals need and deserve greater knowledge and skills so they can contribute to the necessary cultural transformation in the perception and treatment of people with pain. (IOM, 2011, p. 209)

The solution to greater student learning is a more interactive, problem-based curricula centered on competencies to shift the learning and knowledge assessment from traditional disease-related topics, such as anatomy and physiology, to performance and patient outcomes in real-world contexts (Berwick, 2009; Shippee, Shah, May, Mair, \& Montori, 2012). This will include the incorporation of newly available, up-to-date pain competencies (Watt-Watson \& Murinson, 2013). Innovative curricula designs, as well as innovative methods of teaching, are developing. The authors offer strategies, with definitions of the teaching methods used, for incorporating the core pain management competencies (Tables $1-2)$.

Any curriculum change, such as the introduction of pain management core competencies, is highly dependent on the context and culture into which it is delivered. For example, the success of a mandatory 20-hour interfaculty pain curriculum at the University of Toronto is attributed to knowledgeable faculty and clinician facilitators; commitment for the scheduling of needed teaching-learning time; positive and strong evaluation from students, faculty, and administrators; and funding for the development and evaluation of new and existing teaching strategies (Watt-Watson et al., 2004).

Lack of faculty expertise and confidence in teaching about pain, including integrating this knowledge into practice, has been documented for more than 20 years (Duke, Haas, Yarbrough, \& Northam, 2013; Goodrich, 2006; Graffam, 1990; Lasch et al., 2002; Voshall, Dunn, \& Shelestak, 2013). Not only do these factors influence the need for new core competencies, but faculty and clinical educators who have not updated their knowledge of pain may be passing on outdated management strategies and related misbeliefs to the next generation of clinicians. Frenk et al., (2010) described faculty members as agents of 
knowledge transmission and role models for students; therefore, the challenge is to strengthen this resource to provide the most current understanding of pain assessment and management possible. In addition, the recent shift to learner-centered approaches using casebased discussions and critical thinking will play a large role in effective approaches to teaching pain competencies.

Administrative support is essential to provide opportunities for curriculum meetings; consultations with experts in pedagogy, andragogy, and pain; and scheduling of time and physical space within current offerings. Commitment from deans and curriculum chairs is important to champion pain as a learning priority and the need to graduate excellent, competent practitioners in this very common and high-priority area of clinical practice. Funding for innovative strategies, such as simulation of pain scenarios, may be needed, and iterative evaluation of the process and learning outcomes is essential.

The science of knowledge translation and sustainability is complex, but it needs to be strategically linked with new knowledge generation and skills to effectively change provider and patient outcomes. Competencies need to evolve and be representative of the increasing complexity of pain and assessment for patients across the lifespan and in diverse contexts. This requires a favorable and supportive context, administrative support, and effective facilitation methods, including sustainability strategies, as change champions move to other responsibilities.

\section{INCENTIVES FOR INCORPORATING PAIN COMPETENCIES INTO NURSING EDUCATION}

It is essential that competencies for pain management in pre-licensure nursing education be consistent and measurable across nursing education programs. Incentive or motivations for incorporating pain competencies promote the needs of our society (Frenk et al., 2010). Incentives can be created in the following three ways: (a) through quality standards, (b) in accreditation and licensure requirements, and (c) in regulations. Some of these incentives are grounded in the clinical environment, in which pressures for improving pain care are rising. Expectations of the academic setting to prepare graduates with the knowledge and skills to meet the current demands of the workforce can be powerful drivers of change. Academicclinical partnerships can develop effective collaborative approaches to addressing the pain management core competencies when incentives affecting both settings are understood and aligned.

\section{Quality Standards}

Consistent with the core competencies for pain management (Fishman et al., 2013), the National League for Nursing Public Policy Agenda (2015) is striving for interprofessional team-based education and care to improve the care provided by delivery models in health systems. Quality standards in education through the baccalaureate nursing Essentials drive curriculum development and establish financial incentive, given the consequences of not achieving these standards. Establishing the core competencies for pain management as integral in the baccalaureate Essentials used in the American Association of College of 
Nursing accreditation processes would create a strong incentive for action by faculty and administrators.

The IOM (2011) has called for a cultural transformation to the way pain is viewed and treated. This involves improving the education of all health care professionals, including nurses. Pain management is foundational to all health care, and quality standards have been developed for education and practice (ANA, 2005; Gordon et al., 2005; Zorek \& Raehl, 2013). In a joint effort, the ANA (2005) and the American Society for Pain Management Nursing (2014) created quality standards in Pain Management Nursing: Scope and Standards of Practice, pending approval by the ANA, that incorporate pain management into the role of the $\mathrm{RN}$ and the advanced practice $\mathrm{RN}$. These standards contain information on knowledge of assessment, diagnosis, outcome identification, planning, implementation (including coordination of care, health teaching and health promotion, consultation, and prescriptive authority and treatment), and evaluation. In 2010, the ANA Board of Directors approved the position statement, Registered Nurses' Roles and Responsibilities in Providing Expert Care and Counseling at the End of Life. That document also endorses the roles and responsibilities of RNs to provide expert end-of-life care, asserting that nurses "provide aggressive pain control and symptom relief for patients at the end of life" (ANA, 2010, p. 2).

In addition, two other nursing-relevant agencies- the National Quality Forum and the National Database of Nursing-Sensitive Quality Indicators ${ }^{\circledR}$ —addressed pain management in their standards. The National Quality Forum adopted "assessment and management of conditions and symptoms in patients, including pain, dyspnea, weight loss, weakness, nausea, serious bowel problems, delirium, and depression" (National Quality Forum, 2012, p. 1). In 1998, the National Database of Nursing-Sensitive Quality Indicators incorporated patient satisfaction in pain management as one of the 10 nursing-sensitive quality indicators (Montalvo, 2007).

The quality standards described above demonstrate the priorities inside and outside of academia to ensure competence in addressing the challenges of pain and its related symptoms. These standards should establish an imperative for prelicensure curricula that incorporates the pain management core competencies.

\section{Accreditation and Licensure}

The Commission on Collegiate Nursing Education ensures the quality and integrity of baccalaureate, graduate, and residency programs in nursing and provides accreditation based on established standards and expectations. The Commission on Collegiate Nursing Education endorsed the pain management core competencies. Expectations that academic programs will address the pain management core competencies in prelicensure curricula is an important incentive for nursing programs.

The Joint Commission accreditation process provides incentives to health systems that can be impacted by academic partners. The Joint Commission pain management standards offer opportunities to improve pain assessment, management, and documentation in health care facilities throughout the country (Berry \& Dahl, 2000). The Joint Commission standards require that nurses assess, intervene, and reassess the outcomes of their pain management 
interventions. If these standards are not met, then federal and state funding are revoked until the quality of care improves to meet these standards. The Joint Commission accreditation also requires that competencies are ensured through education and training for hospitals to meet the standard (The Joint Commission, 2012). Expecting prelicensure nursing graduates to enter health care organizations with core pain management competencies should be a driver for nurse educators.

The National Council of State Boards of Nursing (2007), responsible for licensing examinations for baccalaureate nurse graduates, wrote the Medication Assistant-Certified Model Curriculum that incorporates observing, reporting, and relieving pain; however, that is the only document from this organization that addresses pain. A strong commitment by the National Council of State Boards of Nursing, with increased emphasis on the RN licensing examination, for incorporating core pain management competencies into expectations for prelicensure nursing graduates and codifying them would create an important incentive for academic programs.

\section{Regulations}

Health care agencies are faced with regulations that highlight the importance of and expectations for effective pain management. These regulations also pressure academic programs to meet the demands of the work setting for an entry-level workforce equipped to provide quality care. For example, the Centers for Medicare and Medicaid Services (2014) uses the Hospital Consumer Assessment of Healthcare Providers and Systems (HCAHPS) survey to generate standardized and objective information about patients' viewpoints of care. The "top-box" (or highest rated) five HCAHPS composites include pain management, in addition to communication with nurses, communication with doctors, responsiveness of hospital staff, and communication about medicines (Centers for Medicare and Medicaid Services, 2014, p. 164). High scores on these HCAHPS items are related to higher reimbursement levels through the Centers for Medicare and Medicaid Services. In home health care agencies, the quality measures for pain are linked to improvement in pain interfering with activity (Medicare Payment Advisory Commission, 2013, p. 164). Nursing and other disciplines prepared in the pain management core competencies would be assets to their organizations in meeting regulatory expectations.

\section{CONCLUSIONS}

Establishing the importance of incorporating core competencies for pain management into the prelicensure education of all nurses is the primary goal of this article. The authors have described significant gaps in the current education system and a national consensus project initiative to advance the core competencies for pain management for all health care prelicensure students. Nursing needs to take the lead in establishing a mandate through its accreditation and certification bodies for ensuring that these competencies are achieved by all RN graduates. The authors have addressed the challenges anticipated and provided potential strategies and resources to support faculty and leadership in this endeavor. Ensuring that all prelicensure nursing graduates demonstrate the core competencies for pain management is a crucial step toward improving pain care in the United States. Nurses 
meeting the core competencies in pain management will be strong partners in interprofessional teams committed to quality pain care for all who enter the health care system.

\section{Acknowledgments}

The Interprofessional Pain Management Competency Program was funded through a grant from the Mayday Fund. Dr. St. Marie received funding for a Postdoctoral Fellowship in Pain and Associated Symptoms: Nurse Research Training (NINR/NIH, T32 NR011147).

The authors thank Jennifer Mongoven for her administrative support of the project.

\section{REFERENCES}

Al Khalaileh M, Al Qadire M. Pain management in Jordan: Nursing students' knowledge and attitude. British Journal of Nursing. 2013; 22:1234-1240. [PubMed: 24280924]

American Association of Colleges of Nursing. The essentials of baccalaureate education for professional nursing practice. 2008 Retrieved from http://www.aacn.nche.edu/education-resources/ BaccEssentials08.pdf.

American Nurses Association. Pain management nursing: Scope and standards of practice. Silver Spring, MD: Author; 2005.

American Nurses Association. Position statement: Registered nurses' roles and responsibilities in providing expert care and counseling at the end of life. 2010 Retrieved from http:// www.nursingworld.org/mainmenucategories/ethicsstandards/ethics-position-statements/ etpain14426.pdf.

American Nurses Association. Code of ethics for nurses with interpretive statements. 2015 Retrieved from http://www.nursingworld.org/MainMenuCategories/EthicsStandards/CodeofEthicsforNurses/ Code-of-Ethics-For-Nurses.html.

American Society for Pain Management Nursing. American Society for Pain Management Nursing ${ }^{\circledR}$ advanced practice portfolio for recognition as an advanced practice pain management nurse. 2014 Retrieved from http://www.aspmn.org/documents/ASPMN\%20APRN\%20Recognition $\% 202014 \% 20$ Application.pdf.

Arwood E, Rowe JM, Singh NS, Carr DB, Herr KA, Chou R. Implementing a paradigm shift: Incorporating pain management competencies into pre-licensure curricula. Pain Medicine. 2014; 16:291-300. [PubMed: 25244226]

Berry PH, Dahl JL. The new JCAHO pain standards: Implications for pain management nurses. Pain Management Nursing. 2000; 1:3-12. [PubMed: 11706454]

Berwick DM. What 'patient-centered' should mean: Confessions of an extremist. Health Affairs (Millwood). 2009; 28:w555-w565.

Briggs CL. What were they thinking? Nursing students' thought processes underlying pain management decisions. Nursing Education Perspectives. 2010; 31:84-88. [PubMed: 20455363]

Briggs EV, Carr EC, Whittaker MS. Survey of undergraduate pain curricula for healthcare professions in the United Kingdom. European Journal of Pain. 2011; 15:789-795. [PubMed: 21330174]

Centers for Medicare \& Medicaid Services. CAHPS ${ }^{\circledR}$ Hospital Survey (HCAHPS): Quality assurance guidelines, version 9.0. 2014 Retrieved from http://www.hcahpsonline.org/Files/HCAHPS \%20QAG\%20V9\%200\%20MARCH\%202014.pdf.

Chiu LH, Trinca J, Lim LM, Tuazon JA. A study to evaluate the pain knowledge of two subpopulations of final year nursing students: Australia and Philippines. Journal of Advanced Nursing. 2003; 41:99-108. [PubMed: 12519293]

Choinière M, Watt-Watson J, Victor JC, Baskett RJF, Bussières JS, Carrier M, Taillefer M-C. Prevalence of and risk factors for persistent postoperative nonanginal pain after cardiac surgery: A 2-year prospective multicentre study. CMAJ. 2014; 186:E213-E223. [PubMed: 24566643]

Doorenbos AZ, Gordon DB, Tauben D, Palisoc J, Drangsholt M, Lindhorst T, Loeser JD. A blueprint of pain curriculum across prelicensure health sciences programs: One NIH pain consortium center 
of excellence in pain education (CoEPE) experience. Journal of Pain. 2013; 14:1533-1538. [PubMed: 24094694]

Duke G, Haas BK, Yarbrough S, Northam S. Pain management knowledge and attitudes of baccalaureate nursing students and faculty. Pain Management Nursing. 2013; 14:11-19. [PubMed: 23452522]

Epstein RM, Hundert EM. Defining and assessing professional competence. JAMA. 2002; 287:226235. [PubMed: 11779266]

Fishman SM, Young HM, Lucas Arwood E, Chou R, Herr K, Murinson BB, Strassels SA. Core competencies for pain management: Results of an interprofessional consensus summit. Pain Medicine. 2013; 14:971-981. [PubMed: 23577878]

Frenk J, Chen L, Bhutta ZA, Cohen J, Crisp N, Evans T, Zurayk H. Health professionals for a new century: Transforming education to strengthen health systems in an interdependent world. Lancet. 2010; 376:1923-1958. [PubMed: 21112623]

Gan TJ, Habib AS, Miller TE, White W, Apfelbaum JL. Incidence, patient satisfaction, and perceptions of post-surgical pain: Results from a US national survey. Current Medical Research and Opinion. 2014; 30:149-160. [PubMed: 24237004]

Gianni W, Madaio RA, Di Cioccio L, D’Amico F, Policicchio D, Postacchini D, Zuccaro SM. Prevalence of pain in elderly hospitalized patients. Archives of Gerontology and Geriatrics. 2010; 51:273-276. [PubMed: 20031238]

Goodrich C. Students' and faculty members' knowledge and attitudes regarding pain management: A descriptive study. Journal of Nursing Education. 2006; 45:140-142. [PubMed: 16562805]

Gordon, DB. Quality evaluation and improvement. In: St. Marie, B., editor. Core curriculum for pain management nursing. 2nd ed.. Dubuque, IA: Kendall Hunt; 2010. p. 645-658.

Gordon DB, Dahl JL, Miaskowski C, McCarberg B, Todd KH, Paice JA, Carr DB. American Pain Society recommendations for improving the quality of acute and cancer pain management: American Pain Society Quality of Care Task Force. Archives of Internal Medicine. 2005; 165:1574-1580. [PubMed: 16043674]

Graffam S. Pain content in the curriculum-A survey. Nurse Educator. 1990; 15:21-23. [PubMed: 2377325]

Herr K, Titler M. Acute pain assessment and pharmacological management practices for the older adult with a hip fracture: Review of ED trends. Journal of Emergency Nursing. 2009; 35:312-320. [PubMed: 19591725]

Institute of Medicine. Relieving pain in America: A blueprint for transforming prevention, care, education, and research. Washington, DC: National Academies Press; 2011.

International Association for the Study of Pain. IASP curricula. 2012 Retrieved from http://www.iasppain.org/Education/CurriculaList.aspx?navItemNumber=647.

The Joint Commission. Pain management. 2012 Retrieved from http://www.jointcommission.org/ topics/pain_management.aspx.

Lasch K, Greenhill A, Wilkes G, Carr D, Lee M, Blanchard R. Why study pain? A qualitative analysis of medical and nursing faculty and students' knowledge of and attitudes to cancer pain management. Journal of Palliative Care. 2002; 5:57-71.

Medicare Payment Advisory Commission. Home health care services; Report to the Congress: Medicare payment policy. 2013. p. 185-211.Retrieved from http://www.medpac.gov/documents/ reports/mar13_ch09.pdf?sfvrsn=0

Montalvo I. The National Database of Nursing Quality Indicators ${ }^{\circledR}\left(\mathrm{NDNQI}^{\circledR}\right)$. The Online Journal of Issues in Nursing. 2007; 12(3) Manuscript 2.

National Council of State Boards of Nursing. Medication assistant-certified (MA-C) curriculum. 2007 Retrieved from https://www.ncsbn.org/3931.htm.

National League for Nursing. Public policy agenda 2015-2016. 2015 Retrieved from http:// www.nln.org/docs/default-source/advocacy-public-policy/public-policy-brochure2015-2016.pdf? sfvrsn=0.

National Quality Forum. Endorsement summary: Palliative care and end-of-life care measures. 2012 Retrieved from http://www.qualityforum.org/News_And_Resources/Endorsement_Summaries/ Endorsement_Summaries.aspx. 
Patel KV, Guralnik JM, Dansie EJ, Turk DC. Prevalence and impact of pain among older adults in the United States: Findings from the 2011 National Health and Aging Trends Study. Pain. 2013; 154:2649-2657. [PubMed: 24287107]

Plaisance L, Logan C. Nursing students' knowledge and attitudes regarding pain. Pain Management Nursing. 2006; 7:167-175. [PubMed: 17145491]

Prem V, Karvannan H, Chakravarthy R, Binukumar B, Jaykumar S, Kumar SP. Attitudes and beliefs about chronic pain among nurses-biomedical or behavioral? A cross-sectional survey. Indian Journal of Palliative Care. 2011; 17:227-234. [PubMed: 22346048]

Puls-McColl PJ, Holden JE, Buschmann MT. Pain management assessment of surgical nurses' knowledge. MEDSURG Nursing. 2001; 10:185-191.

Rahimi-Madiseh M, Tavakol M, Dennick R. A quantitative study of Iranian nursing students' knowledge and attitudes towards pain: Implication for education. International Journal of Nursing Practice. 2010; 16:478-483. [PubMed: 20854345]

Registered Nurses' Association of Ontario. Assessment and management of pain. 3rd ed.. Toronto, ON: Author; 2013.

Samuels JG, Leveille DM. Senior nursing students' clinical judgment in pain management. Nurse Educator. 2010; 35:220-224. [PubMed: 20729684]

Shaw S, Lee A. Student nurses' misconceptions of adults with chronic nonmalignant pain. Pain Management Nursing. 2010; 11:2-14. [PubMed: 20207323]

Shippee ND, Shah ND, May CR, Mair FS, Montori VM. Cumulative complexity: A functional, patient-centered model of patient complexity can improve research and practice. Journal of Clinical Epidemiology. 2012; 65:1041-1051. [PubMed: 22910536]

Sloman R, Ahern M, Wright A, Brown L. Nurses' knowledge of pain in the elderly. Journal of Pain and Symptom Management. 2001; 21:317-322. [PubMed: 11312046]

Stanley M, Pollard D. Relationship between knowledge, attitudes, and self-efficacy of nurses in the management of pediatric pain. Pediatric Nursing. 2013; 39:165-171. [PubMed: 24027950]

Taylor EM, Boyer K, Campbell FA. Pain in hospitalized children: A prospective cross-sectional survey of pain prevalence, intensity, assessment and management in a Canadian pediatric teaching hospital. Pain Research and Management. 2008; 13:25-32. [PubMed: 18301813]

Tsang A, Von Korff M, Lee S, Alonso J, Karam E, Angermeyer MC, Watanabe M. Common chronic pain conditions in developed and developing countries: Gender and age differences and comorbidity with depression-anxiety disorders. Journal of Pain. 2008; 9:883-892. [PubMed: 18602869]

van den Beuken-van Everdingen MHJ, de Rijke JM, Kessels AG, Schouten HC, van Kleef M, Patijn J. Prevalence of pain in patients with cancer: A systematic review of the past 40 years. Annals of Oncology. 2007; 18:1437-1449. [PubMed: 17355955]

Voshall B, Dunn KS, Shelestak D. Knowledge and attitudes of pain management among nursing faculty. Pain Management Nursing. 2013; 14:e226-e235. [PubMed: 24315276]

Watt-Watson J, Hunter J, Pennefather P, Librach L, Raman-Wilms L, Schreiber M, Salter M. An integrated undergraduate pain curriculum, based on IASP curricula, for six health science faculties. Pain. 2004; 110:140-148. [PubMed: 15275761]

Watt-Watson J, McGillion M, Hunter J, Choiniere M, Clark AJ, Dewar A, Webber K. A survey of prelicensure pain curricula in health science faculties in Canadian universities. Pain Research and Management. 2009; 14:439-444. [PubMed: 20011714]

Watt-Watson J, Murinson BB. Current challenges in pain education. Pain Management. 2013; 3:351357. [PubMed: 24654868]

Watt-Watson J, Peter E, Clark AJ, Dewar A, Hadjistavropoulos T, Morley-Forster P, Campbell-Yeo M. The ethics of Canadian entry-to-practice pain competencies: How are we doing? Pain Research and Management. 2013; 18:25-32. [PubMed: 23457683]

Watt-Watson J, Siddall PJ. Improving pain practices through core competencies. Pain Medicine. 2013; 14:966-967. [PubMed: 23647689]

Wilkes G, Lasch KE, Lee JC, Greenhill A, Chiri G. Evaluation of a cancer pain education module. Oncology Nursing Forum. 2003; 30:1037-1043. [PubMed: 14603361] 
Zorek J, Raehl C. Interprofessional education accreditation standards in the USA: A comparative analysis. Journal of Interprofessional Care. 2013; 27:123-130. [PubMed: 22950791] 


\section{TABLE 1}

Pain Management Domains, Core Competencies, and Strategies for Integrating Pain Competencies Into Prelicensure Nursing Education

\author{
Domain and Core Competency \\ Domain One \\ Multidimensional nature of pain: What is pain? \\ This domain focuses on the fundamental concepts of \\ pain, \\ including the science, nomenclature, and experience of \\ pain and \\ the impact of pain on the individual and society. \\ Competencies \\ Explain the complex, multidimensional and individual- \\ specific \\ nature of pain. \\ Present theories and science for understanding pain. \\ Define terminology for describing pain and associated \\ conditions. \\ Describe the impact of pain on society. \\ Explain how cultural, institutional, societal, and \\ regulatory \\ influences affect assessment and management of pain.
}

Domain Two

Pain assessment and measurement: How is pain recognized?

This domain relates to how pain is assessed, quantified, and

communicated, in addition to how the individual, health system,

and society affect these activities.

Competencies

Use valid and reliable tools for measuring pain and associated

symptoms to assess and reassess related outcomes as

appropriate

for the clinical context and population.

Describe patient, provider, and system factors that can facilitate or

interfere with effective pain assessment and management.

Assess patient preferences and values to determine pain-

related goals and priorities.

Demonstrate empathic and compassionate

communication during

pain assessment.

Domain Three

Management of pain: How is pain relieved?

This domain focuses on collaborative approaches to decision

making, diversity of treatment options, the importance of

patient

agency, risk management, flexibility in care, and treatment

based

on appropriate understanding of the clinical condition. Competencies

Demonstrate the inclusion of patient and others, as appropriate, in

\section{Teaching Method/Example}

CB, D, P, O

- Include content in anatomy and physiology, foundations of nursing practice, and health policy courses (the depth of pathophysiology would include central and peripheral sensitization, alterations in nociceptive processes leading to chronic pain, confounding psychosocial factors leading to chronic pain).

- $\quad$ Use a Jeopardy! ${ }^{\circledR}$ or other gaming approach for understanding relevant terminology and definitions.

- Ask students to share their experiences of pain.

- If students are not yet in clinical rotations, talk about pain reported in the media; this may include images of people in pain, as well as discussion on the use of opioids and addiction. Discuss literature that includes pain (e.g., The Body in Pain by Elaine Scarry, The Problem of Pain by C.S. Lewis).

- For students who have had some clinical experiences, process the way they have seen patients assessed and treated; discuss biases that may have been exhibited by staff or the patient (e.g., stigmatization and marginalization, which is well documented in research).

- In health policy classes, review issues related to the state's prescribing and administering of opioids, as well as the impact of pain on the community (e.g., opioid prescribing, prescription monitoring programs, access to pain management, disparities).

$\mathrm{CB}, \mathrm{S}, \mathrm{CE}$

- Use pain assessment tools during clinical experiences; discuss the benefits and limitations of each tool for specific populations.

- Present cases that allow the discussion of barriers and facilitators of pain assessment and management. Include nonverbal pain assessment tools, age-specific tools, and illustrations of assessment challenges.

- Simulate pain assessment in a variety of clinical scenarios and contexts; encourage learners to carefully evaluate communication skills for each member of the group (e.g., pick out stigmatizing terms and figure out the terms that will not do that). Identify body language that portrays indifference or not believing the patient.

- Observe pain assessment during clinical experiences; offer constructive feedback.

- Develop a plan of care to manage pain in the clinical setting, using assessment findings while integrating patient preferences and goals.

$\mathrm{CB}, \mathrm{D}, \mathrm{P}, \mathrm{S}, \mathrm{T}, \mathrm{CE}$

- Include pain-related content in pharmacology courses and specific discussions around nonopioids, opioids, and adjuvant analgesics (e.g., define multimodal analgesia and how it is different from polypharmacy). Incorporate patient safety with medications.

- Incorporate issues related to substance use disorder in courses addressing mental health issues. Include differentiating-seeking relief for pain from prescription opioid misuse or abuse. 
\begin{tabular}{|l} 
Domain and Core Competency \\
\hline the education and shared decision-making process for pain
\end{tabular} care.

Identify pain treatment options that can be accessed in a comprehensive pain management plan.

Explain how health promotion and self-management strategies

are important to the management of pain.

Develop a pain treatment plan based on the benefits and risks of

available treatments.

Monitor effects of pain management approaches to adjust the

plan of care as needed.

Differentiate physical dependence, substance use disorder,

misuse, tolerance, addiction, and nonadherence and how

these

conditions impact pain and function.

Develop a treatment plan that takes into account the differences

between acute pain, acute-on-chronic pain, chronic-

persistent

pain, and pain at end of life.

Domain Four

Clinical conditions: How does context influence pain management?

This domain focuses on the role of the clinician in the application

of the competencies developed in domains one to three and in

the context of varied patient populations, settings, and care teams.

Competencies

Describe the unique pain assessment and management needs of

special populations.

Explain how to assess and manage pain across settings and

transitions of care.

Describe the roles, scope of practice, and contributions of the

different professions within a pain management care team.

Implement an individualized pain management plan that integrates the perspectives of patients, their social support systems, and health care providers in the context of available

resources

Describe the role of the clinician as an advocate in assisting

patients to meet treatment goals.
Teaching Method/Example

- In team-based learning, groups can investigate specific acute, chronic, cancer, acute-on-chronic, or end-of-life painful syndromes, developing a treatment plan that includes self-management strategies.

- $\quad$ Observe collaborative pain care and diversity of treatment options during clinical experiences by participating in an interdisciplinary pain management program.

- During clinical experiences, identify potential pain treatment options, articulate the risks and benefits, and develop a safe and effective treatment plan.

\section{$\mathrm{CB}, \mathrm{P}, \mathrm{S}, \mathrm{CE}$}

- Devote at least one clinical conference to pain issues; have students address pain assessment and management, even when pain is not the primary concern for a specific patient; discuss barriers and interventions to ensure seamless transitions in pain care; address the roles of various professionals in relieving pain. Attend interprofessional team rounding, care conference, or journal club, and, specifically, prepare an essay on how nursing contributes to the team.

- Discuss and generate examples of current insights regarding pain, including ineffectively treated acute pain leading to chronic pain, and changes occurring in the brain when experiencing pain.

- Simulate scenarios where the nurse can serve as an advocate for a patient with pain (e.g., justifying the use of an elevated dose of an opioid; consideration of other treatment options, such as complementary therapies; and support for pain management in individuals with substance abuse disorder).

- Have students attend a support group meeting for individuals with chronic pain disorders (e.g., fibromyalgia, sickle cell disease, neuropathy).

- Have the students write a reflective narrative and tell the story from the patient's perspective. Ask them to describe the patient's social and financial support. What are the barriers to care for the patient and caregiver? What are the environmental challenges the patient faces? How does the patient define quality of life? Describe the interaction between the patient and family and health care system. How has the patient adapted to the pain? How do the patient and caregivers see their future?

Note. $\mathrm{CB}=$ case-based learning; $\mathrm{D}=$ didactic $; \mathrm{P}=$ problem-based learning; $\mathrm{O}=$ other; $\mathrm{S}=$ simulation-based learning; $\mathrm{CE}=$ clinical experiences; $\mathrm{T}$ $=$ team-based learning. 
TABLE 2

\section{Definitions of Teaching Methods for Integrating Pain Competencies Into Prelicensure Nursing Education}

\begin{tabular}{|ll|}
\hline Teaching Method & Description \\
\hline Case-based learning & $\begin{array}{l}\text { Use of real or simulated stories that include patient problems and symptoms. Students analyze the stories and, } \\
\text { working in small groups, arrive at a solution by applying course concepts and evidence found in the literature. } \\
\text { Role-playing would help to solidify the communication strategy of difficult situations. }\end{array}$ \\
Didactic & A PowerPoint ${ }^{\circledR}$ presentation or lecture that may include a brief question-and-answer session. \\
Problem-based learning & $\begin{array}{l}\text { Focused, experiential learning that is organized around the investigation of clinical problems. Learner groups are } \\
\text { presented with a case, and they set their own learning objectives, often dividing the work, teaching each other, } \\
\text { guided [by others in the group or by faculty]. }\end{array}$ \\
Simulation-based learning & $\begin{array}{l}\text { Simulations can be low tech or high tech, can duplicate clinical scenarios, and allow learners to engage in } \\
\text { activities that approximate realistic situations. }\end{array}$ \\
Team-based learning & $\begin{array}{l}\text { Teacher-directed method for incorporating small-group active participation in large-group educational settings. } \\
\text { Learners must actively participate inside and outside of class (preparation and discussion). Team-based learning } \\
\text { shifts away from facts to application. }\end{array}$ \\
Observation of and practice in inpatient and/or outpatient health care. \\
Other
\end{tabular}

Adapted from “A Blueprint of Pain Curricuum Across Pre-Licensure Health Sciences Programs: One NIH Pain Consortium Center of Excellence in Pain Education (CoEPE) Experience," by A.Z. Doorenbos, D.B. Gordon, D. Tauben, J. Palisoc, M. Drangsholt, T. Lindhorst, J. Danielson, J. Specter, R. Ballweg, L. Vorvick, and J. D. Loeser, 2013, Journal of Pain, 14(12):1533-1538. Copyright 2013 by Elsevier. Adapted and reprinted with permission. 